\title{
Herculano Interativa - Ciberarqueologia e Educação no desenvolvimento do jogo O Último Banquete em Herculano
}

\author{
Maria Isabel D'Agostino Fleming* \\ Alex da Silva Martire** \\ Alessandro Mortaio Gregori***
}

\begin{abstract}
FLEMING, M.I.D'A.; MARTIRE, A.S.; GREGORI, A.M. Herculano Interativa - Ciberarqueologia e Educação no desenvolvimento do jogo O Último Banquete em Herculano. R. Мuseu Arq. Etn., 35: 36-43, 2020.
\end{abstract}

Resumo: $\mathrm{O}$ artigo tem por objetivo apresentar o processo de desenvolvimento do primeiro jogo eletrônico produzido pelo Laboratório de Arqueologia Romana Provincial do Museu de Arqueologia e Etnologia da Universidade de São Paulo (LARP/MAE-USP) denominado O Último Banquete em Herculano. Em um primeiro momento, serão discutidos os aspectos técnicos da produção do jogo, elencando os processos de coleta de material, escrita de roteiro, modelagem 3D e programação. Em seguida, será pormenorizada a proposta do jogo aplicado à Educação, calcado na elaboração de um Guia Didático para professores com roteiros de aulas e usos do jogo em salas de aula.

Palavras-chave: Ciberarqueologia; Roma Antiga; Videogames; Educação; Ensino básico.

\section{Introdução}

O Ultimo Banquete em Herculano (doravante OUBEH) foi concebido como um videogame do gênero adventure point'n'click (apontar e clicar) e é resultado do trabalho coletivo dos pesquisadores do Laboratório de Arqueologia Romana Provincial do Museu de Arqueologia e Etnologia da USP

* Professora Sênior de Arqueologia Clássica, Coordenadora do Laboratório de Arqueologia Romana Provincial (LARP/MAE-USP). <mi.fleming@usp.com.br>

** Pesquisador associado do Laboratório de Arqueologia Romana Provincial (LARP/MAE-USP). Pós-doutorando da Faculdade de Filosofia e Ciências Humanas (FAFICH-UFMG), Dep. de Pós-Graduação em Antropologia. <alexmartire@gmail.com>

*** Pesquisador associado do Laboratório de Arqueologia Romana Provincial (LARP/MAE-USP). Doutorando na Faculdade de Educação da Universidade de São Paulo (FE-USP).<amortaio@hotmail.com>
(LARP/MAE-USP) envolvidos com a pesquisa em Humanidades Digitais e Ciberarqueologia ${ }^{1}$. Seu desenvolvimento partiu de uma proposição conceitual: trazer ao público uma narrativa lúdica direcionada ao aprendizado de temas e conceitos histórico-arqueológicos próprios do mundo romano. O trabalho com o jogo ocorreu ao longo dos anos 2017 e 2018 e, até a data de seu lançamento, outubro de 2018, revelou-se um desafio para o LARP.

Este artigo apresenta à comunidade acadêmica o desenvolvimento de OUBEH sob dois pontos de vista. Inicialmente, a trajetória de produção do jogo, calcada nos recursos

1 O jogo OUBEH é um dos projetos-piloto educativos do projeto de pesquisa Formas de Contato: Produção, Poder e Simbolismo no Mundo Romano - Laboratório de Arqueologia Romana Provincial - LARP-MAE/USP, financiado pela FAPESP (processo 2015/17836-0). 
gráficos disponíveis para a pesquisa e produção em Ciberarqueologia. Em seguida, expõe a concepção didática do jogo, estruturada na produção de O Último Banquete em Herculano: Guia Didático, publicação que acompanha o jogo e propõe itinerários pedagógicos para o uso do recurso digital em salas de aulas da educação básica² .

\section{Os aspectos técnicos e gráficos}

O desenvolvimento de OUBEH estendeu-se por vinte e um meses, iniciando-se em janeiro de 2017 e sendo encerrado em setembro de 2018. O projeto contou com a participação de treze pesquisadores, sendo onze do LARP (Alessandro M. Gregori, Alex S. Martire, Anisio C. Pereira Filho, Juliana V. Mouro, Lygia F. Rocco, Marcio T. Bastos, Maria Isabel D’A. Fleming, Matheus M. Cruz, Silvana Trombetta, Tomás P. Cafagne e Vagner C. Porto), um da Universidade Federal do Pará (Amanda D. V. Pina), e um da Faculdade de Filosofia, Letras e Ciências Humanas da USP (Vinicius M. Carvalho). A coordenação-geral do projeto foi da Profa. Dra. Maria Isabel D'Agostino Fleming, enquanto a idealização e direção foram do Dr. Alex da Silva Martire. $O$ desenvolvimento de OUBEH passou por três etapas que serão agora brevemente explicitadas, a saber: pré-produção, produção e pós-produção.

\section{Pré-produção}

Nessa etapa, as ideias do grupo referentes ao produto final foram discutidas em reuniões e redigidas em documentos que nortearam seu desenvolvimento. Para OUBEH, foi produzido um documento característico do desenvolvimento de jogos denominado Página Única, no qual constava a síntese do produto (argumento inicial). Esse documento foi utilizado para difundir

2 O jogo e o Guia Didático estão disponíveis no endereço <http://www.larp.mae.usp.br/o-ultimo-banquete-emherculano/download/> a ideia geral do jogo entre os envolvidos de forma esquematizada, orientando a todos durante o restante do desenvolvimento.

Terminado o argumento inicial, os pesquisadores envolveram-se com a redação de quebra-cabeças (puzzles) e diálogos referentes às suas cenas no jogo: cada pesquisador do LARP pôde colaborar dentro de sua área de especialização, fornecendo, assim, como produto final, uma ampla contextualização histórica e arqueológica do cotidiano na cidade antiga de Herculano. Esse conjunto de diálogos e quebra-cabeças foi reunido em um documento denominado Dez Páginas, que aborda todos os aspectos do jogo: jogabilidade, cenários, falas, enigmas, mecânicas, distribuição e extras. Assim, de acordo com o Dez Páginas, tivemos os seguintes cenários da cidade de Herculano presentes em OUBEH: Casa de Netuno e Anfitrite (responsáveis: Dra. Lygia F. Rocco e Me. Anisio C. Pereira Filho); Armazém (responsável: Dra. Maria Isabel D’A. Fleming); Olaria (responsável: Dr. Marcio T. Bastos); Termas (responsável: Dra. Silvana Trombetta); Mercado (responsáveis: Dr. Vagner C. Porto, mestrando Tomás P. Cafagne e graduando Matheus M. Cruz); Área Sacra (doutorando Alessandro M. Gregori); Porto (mestranda Juliana V. Mouro).

Finalizadas a esquematização e redação, foi iniciada a fase de levantamento imagético para servir de referência à modelagem tridimensional da etapa seguinte. Os pesquisadores fizeram o levantamento em bibliografia específica e, principalmente, na base de dados interna do LARP, o Barolo, o qual conta com fotografias das diversas regiões visitadas pelos pesquisadores, incluindo Herculano. As imagens foram essenciais para a construção visual tridimensional, servindo as plantas de edifícios erguidos em Herculano de base para a escala dos ambientes modelados na etapa de Produção.

\section{Produção}

Nesta etapa, o jogo inteiro foi desenvolvido, ou seja, foram realizadas a modelagem dos objetos e a programação da interatividade. 
Herculano Interativa - Ciberarqueologia e Educação no desenvolvimento do jogo O Último Banquete em Herculano R. Museu Arq. Etn., 35: 36-43, 2020.

Tendo por dispositivos-alvo os celulares, ficou estabelecido que os gráficos do jogo seriam low-poly, ou seja, seriam estilizados para terem, em seus modelos, baixo número de polígonos. Essa técnica é bastante utilizada para jogos voltados ao mercado mobile dos celulares. Com o estilo definido, foi dado início à modelagem de cada objeto que compõe as cenas do jogo. Optou-se por uma estrutura modular para as paredes dos edifícios, ou seja, foram modelados objetos fracionados que poderiam, facilmente, ser colocados lado a lado a fim de compor um cenário. A modelagem foi baseada nas referências imagéticas fornecidas pelo grupo de pesquisadores envolvidos. Dessa forma, foram modelados e texturizados, ao todo, 120 objetos 3D no programa Autodesk Maya (FIGURA 1) que, reunidos, contabilizaram 9352 triângulos nas malhas tridimensionais - um valor baixo, condizente com a modelagem estilo low-poly. Após a modelagem, todos os objetos foram exportados com a extensão.FBX.

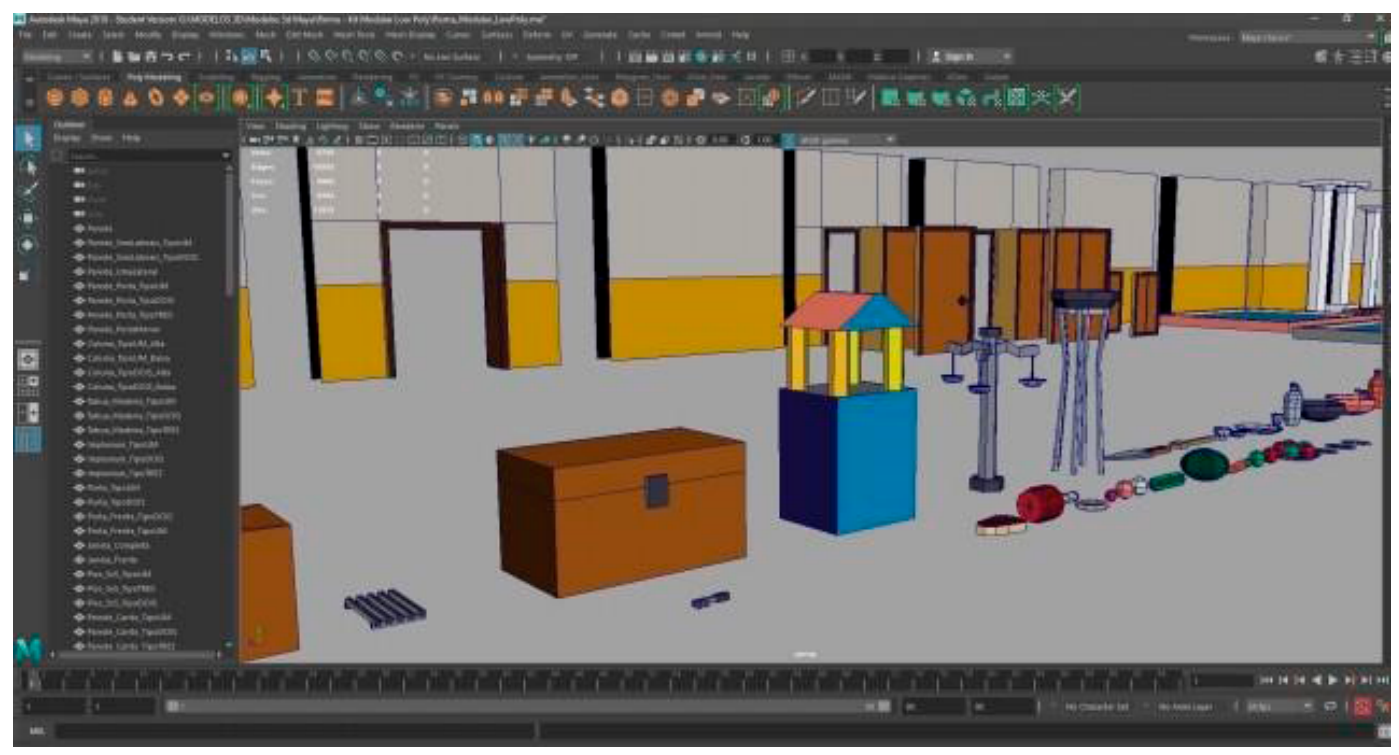

Fig. 1. Modelos 3D dispostos no AutoDesk Maya.

Fonte: Produção própria durante modelagem do jogo.

A interatividade em tempo real do jogador com o dispositivo eletrônico foi realizada com o motor gráfico Unity, para o qual foi utilizada uma ferramenta denominada adventure creator, que fornece todo o material necessário para a produção de jogos estilo adventure point'n'click (FIGURA 2). Com os objetos tridimensionais importados no Unity, cada uma das sete cenas do jogo foi produzida separadamente.

Primeiro, foram colocados nos ambientes os personagens humanos do jogo (previamente modelados no Autodesk Maya e animados com a plataforma online Mixamo) e definido o jogador/ator principal (no caso, o escravizado Septimius). Os demais personagens servem como agentes de interação e são denominados Non-Player Characters (NPC), ou seja, figuras com as quais não é possível jogarmos, mas, apenas, efetuarmos ações, tais como observar ou conversar. Cada NPC recebeu um número de linhas de texto que formam o diálogo com o jogador. Esses textos foram adaptados do material fornecido pelos pesquisadores do projeto totalizando 919 linhas (posteriormente traduzidas para o inglês pelo doutorando Vinicius M. Carvalho). Os diálogos serviram de base para o sequenciamento de ações que o jogador deve realizar a fim de solucionar cada quebra-cabeça do cenário em que está. Essas ações foram posicionadas em objetos específicos 
espalhados pelos cenários e são denominadas hotspots, ou seja, pontos de interesse com os quais há interação.

Os hotspots obedecem a uma lógica construída para que o enigma da cena seja solucionado, fornecendo, dentro do jogo, itens para o inventário do jogador, bem como mudanças de câmera e carregamento de outros cenários. De acordo com a interação com os hotspots e as respostas aos diálogos com NPC, uma série de variáveis são armazenadas na memória do jogo para orientar o jogador sobre as áreas já visitadas e quais elementos da tarefa principal ainda devem ser resgatados para dar continuidade ao objetivo geral (realizar o banquete ao final da noite). Foi também nessa fase da programação de interações que os efeitos sonoros e músicas de fundo foram inseridos no jogo, são elementos que mudam de acordo com os cenários e objetos com os quais o jogador interage.

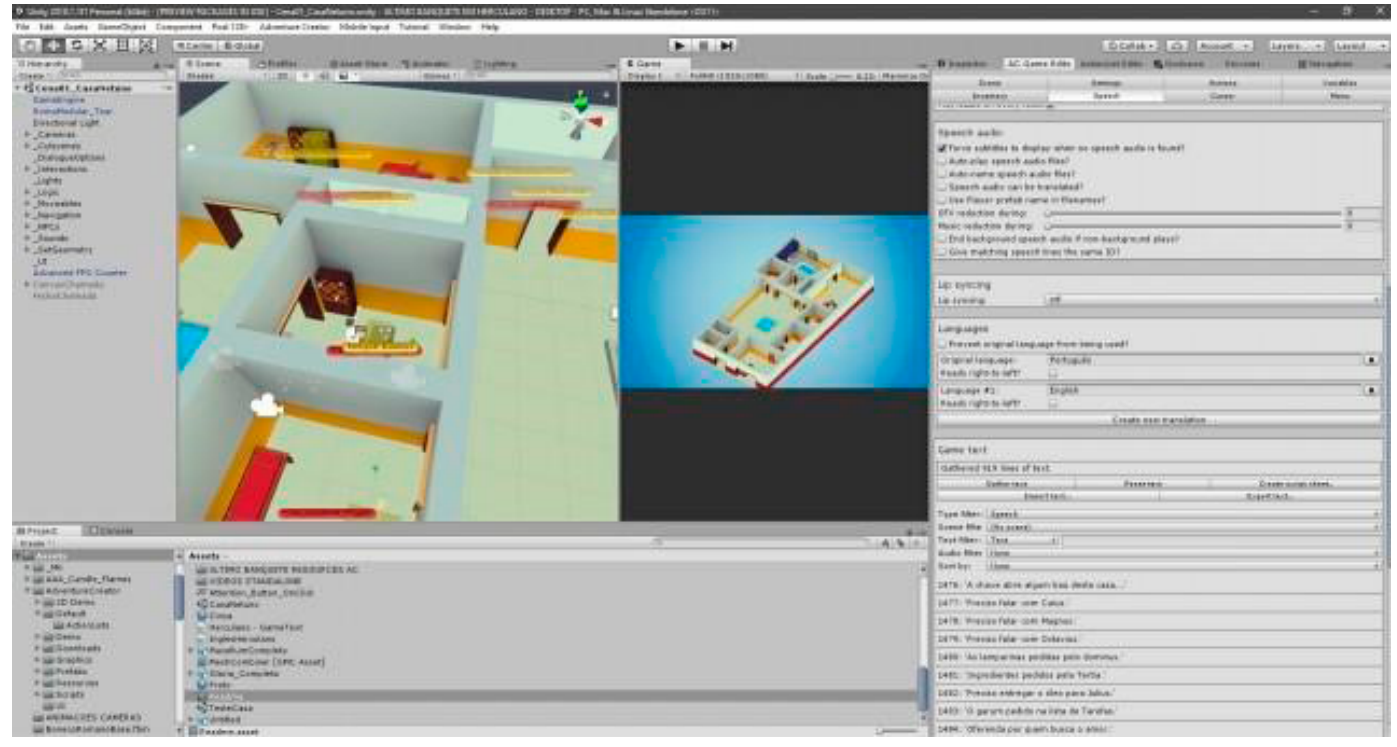

Fig. 2. Programação dentro do motor gráfico Unity.

Fonte: Produção própria durante modelagem do jogo.

Com o fim da produção das interações, ou seja, do jogo em si, foi dado início à edição dos vídeos extras inseridos no produto. A ideia central desses vídeos foi a de aprofundar temáticas levantadas durante o gameplay. Ao todo, foram editados, pelo Dr. Alex Martire, oito vídeos com duração entre 2 e 3 minutos, revisados pela Dra. Maria Isabel D’A. Fleming, narrados pelo Me. Anisio C. Pereira Filho e traduzidos para o inglês pela doutoranda Amanda D. V. Pina; a saber: A cidade de Herculano (texto: graduando Matheus $M$. Cruz); Casa de Netuno e Anfitrite (texto: Dra. Lygia F. Rocco); Área Sacra de Herculano (texto: doutorando Alessandro
M. Gregori); Banquete romano (texto:

Me. Anisio C. Pereira Filho); Economia romana (texto: Dr. Vagner C. Porto e graduando Matheus M. Cruz); Cerâmica romana (texto: Dra. Maria Isabel D’A. Fleming); Prataria romana (texto: Dra. Maria Isabel D’A. Fleming); e Banho romano (texto: Dra. Silvana Trombetta).

\section{Pós-produção}

A partir do Unity, foram exportados três tipos de arquivos executáveis do jogo, cada um para uma plataforma selecionada na etapa de pré-produção: mobile Google Play, App Store e 
Windows (esse sistema operacional em específico foi disponibilizado no website do LARP). Todas as versões foram disponibilizadas gratuitamente. Também, nesta etapa, foi elaborado e distribuído gratuitamente em formato PDF o material voltado para professores. Denominado O Último Banquete em Herculano: Guia Didático, o material de 48 páginas foi redigido pelo doutorando Alessandro M. Gregori e pela doutoranda Amanda D. V. Pina, e editorado pela Dra. Maria Isabel D'A. Fleming. O guia conta com uma contextualização histórica da cidade de Herculano, uma discussão sobre a importância do uso de jogos eletrônicos na Educação, e também propostas de atividades com alunos e planos de aula para professores.

\section{Guia Didático: o videogame como aliado da aprendizagem}

A realização de OUBEH como recurso didático teve como ponto de partida a concepção de que videogames podem e devem ser utilizados como ferramentas para o ensinoaprendizagem. Aponta-se que a inserção de jogos no ensino valoriza, sobretudo, a ludicidade, a leveza do brincar e suas diversas potencialidades como instrumento educativo (Costa 2017: 28). É possível considerá-los uma ferramenta didática, pois permitem ao usuário imersão, interação e envolvimento com um objeto, o qual, ao simular um mundo real ou imaginário, carrega em si questões cognitivas, tais como as resoluções de problemas, as tomadas de decisão, a formalização de regras e o estabelecimento de estratégias.

É importante salientar que nem todo videogame é produzido com o objetivo de suscitar questões de aprendizagem. Trata-se de um instrumento, uma ferramenta com potencial educativo. Sua presença não substitui a mediação docente e os procedimentos próprios da cultura escolar. Como qualquer jogo, torna-se educativo por um processo de formalização educativa, que se origina do olhar de um observador externo envolvido na criação de uma realidade específica para a educação formal (Brougère 2002: 17-18). Assim, ao conceberem OUBEH, os pesquisadores do LARP engajaram-se na construção de situações didáticas provenientes do enredo que suporta a narrativa do videogame, objetivando alcançar situações de aprendizagem que dialogassem com o universo dos programas das disciplinas escolares.

Experiências anteriores do LARP com aplicativos digitais demonstraram que o contato dos educandos com esse tipo de mídia auxilia favoravelmente na aprendizagem, uma vez que o aprendizado interativo possibilita a formulação de hipóteses pelos alunos e o desenvolvimento de respostas para problemas propostos pela própria mídia (Fleming \& Gregori 2017: 75). Concebe-se, portanto, que a utilização da mídia interativa em situações de aprendizagem formais justifica-se, pois a capacidade de proporcionar cognição é intrínseca à sua constituição, desde que utilizada por educadores a partir de recortes didáticos específicos.

Percorrendo-se os cenários de OUBEH, o usuário encontrará objetos e estruturas que compõem a experiência cotidiana dos habitantes de uma cidade romana. Ao se relacionar o jogo à experiência arqueológica, os artefatos são os principais vetores do conhecimento sobre o passado. Aprender sobre o mundo antigo por meio da cultura material favorece a compreensão das relações das sociedades humanas com os ambientes que ocupam e o modo como articulam várias dimensões da vida social com seu cotidiano. Desse modo, o contato do educando com o jogo facilitará a aprendizagem de questões próprias de disciplinas escolares, não apenas de História, mas também de Geografia, Artes e até mesmo das Ciências da Natureza.

A realidade da educação básica no país colabora para a pouca ou ineficiente utilização dos dispositivos digitais aplicados ao ensino. Salas lotadas, professores com poucos recursos e a inexistência de suporte técnico são alguns dos entraves que se colocam quando da aplicação de objetos digitais nas aulas. Contudo, a presença desses objetos deve valer-se de sua flexibilidade, ludicidade e multiplicidade de suportes. Cabe aos educadores encontrar estratégias para burlar os entraves e trazer com mais frequência tais 
recursos para as escolas. É nesse sentido que O Último Banquete em Herculano: Guia Didático se apresenta à comunidade escolar: um material de apoio que acompanha o aplicativo digital e possibilita aos docentes o planejamento de suas atividades com a presença do jogo (FIGURA 3).

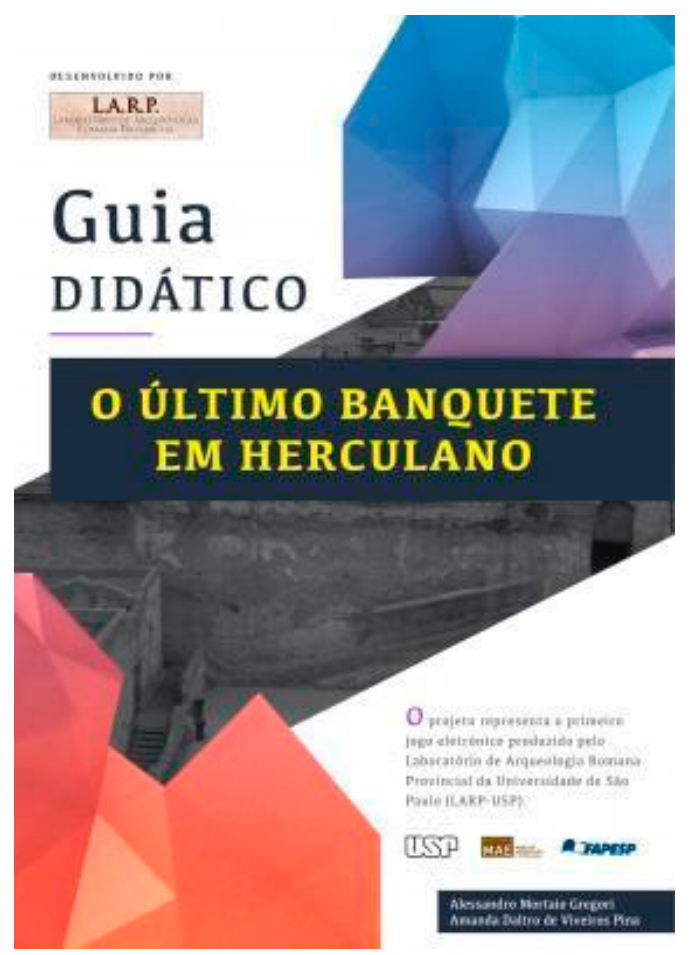

Fig. 3. Reprodução da capa de O Último Banquete em Herculano: Guia Didático.

Fonte: Produção própria durante modelagem do jogo.

O guia divide-se em seis sessões. As três primeiras apresentam as concepções didáticas sobre o uso de videogames em sala de aula, um descritivo sobre modelagem, assim como uma breve contextualização históricoarqueológica sobre a cidade de Herculano. Estão disponíveis, também, textos sobre os personagens do jogo e possibilidades didáticas para se utilizar a cultura material como facilitador de aprendizagens.

Em seguida, apresentam-se aos educadores sugestões de atividades e planos de aulas. As sugestões de atividades centram-se nos cenários do jogo. Por ser concebido como uma narrativa contínua, OUBEH leva o jogador a experimentar diversos cenários característicos do mundo romano: a casa (domus), os banhos públicos (thermae), o mercado, o porto e os templos. Tal opção favorece a exploração desses locais como "panos de fundo" para a prática de situações de aprendizagem. Em uma sequência padronizada, cada sugestão de atividade fornece uma primeira etapa de contextualização, seguindo para a exploração autônoma do cenário pelo educando, uma atividade de debate e, finalmente, uma sugestão avaliativa, compreendida como uma produção original.

Para elucidar essa sequência de atividades, tomemos como exemplo o cenário domus, a casa romana. Seguindo as indicações do guia, na etapa de contextualização, solicitase ao educador que descreva a casa romana ideal para os alunos com apoio de fotos ou vídeos curtos (disponibilizados no website do LARP). A seguir, é proposta a livre circulação dos alunos pelo cenário virtual. Posteriormente, o educador deve incitar um debate entre os alunos. Questões indicadas seriam: Quem é possivelmente o dono dessa casa? Qual cômodo despertou seu interesse? Dê o significado sobre os seguintes termos da domus romana: lararium, tablinium, triclinium e taberna. Por fim, solicita-se aos educandos que criem sua própria casa romana da maneira tradicional - com papel e lápis de cor, ou ainda com auxílio do kit de modelagem 3D disponível online no website do LARP.

Planos de aula nos modelos tradicionais executados pelos professores também se encontram disponíveis no guia. Oferecem-se três opções de abordagem do jogo em sala de aula, considerando-se a disponibilidade de tempo dos professores. O plano de aula de curta duração possui 50 minutos, o intermediário, 1 hora e 40 minutos e o longo, 2 horas e 30 minutos. A partir de uma estrutura fixa - procedimentos metodológicos, objetivos, atividades e avaliação -, os planos de aula foram concebidos à maneira formal, possibilitando que o educador os inclua em seus planejamentos futuros.

É evidente que as sugestões de atividades com cenários do jogo e os planos de aula, 
ainda que apresentem uma estrutura formal, não foram elaborados para serem fixos. Permitem também ao educador a apropriação do material de forma autônoma. Desde os primeiros produtos do LARP notou-se a demanda por um material mais elaborado e que operasse como um manual, por isso o guia foi concebido com o intuito de orientar o trabalho pedagógico.

O capitulo final do guia traz aos educadores uma lista bibliográfica atualizada, com obras sobre Ensino e Games, livros paradidáticos e sobre a história de Roma. Apresentam-se, também, websites com conteúdos interativos sobre os antigos romanos. A preferência foi por oferecer ao público mídias acessíveis sempre em língua portuguesa.

A divulgação dos produtos do LARP e os posteriores workshops com educadores aproximaram o público leigo do universo acadêmico (Fleming \& Gregori 2017: 76). A realização de OUBEH é um resultado dessas frutíferas trocas. A sensibilização e o diálogo com os educadores levantaram uma série de questões sobre a aprendizagem e a dinâmica de aulas suportadas por recursos digitais. Foi possível, por meio de tais trocas, construir um material coerente, respaldado pela pesquisa científica, porém direcionado às realidades das escolas do país.

\section{Considerações finais}

O processo de produção de OUBEH mobilizou os pesquisadores do LARP para a realização de um projeto inédito na trajetória acadêmica do laboratório: conceber um jogo eletrônico em que os pressupostos da Ciberarqueologia promovessem situações de aprendizagem específicas direcionadas ao público em idade escolar. O produto final, disponibilizado gratuitamente no site do laboratório, proporciona uma experiência contextualizada única, uma vez que a interatividade e o raciocínio arqueológico mesclam-se, possibilitando situações específicas de aprendizagem.

Em um mundo cada vez mais cibertecnológico os recursos digitais operam como grandes aliados da aprendizagem. Ainda que julgados pelo senso comum como meros passatempos, ou estímulos que possam resultar em vício ou desvio de conduta, os videogames, postos em situações didáticas, permitem que a aprendizagem seja não apenas prazerosa, mas viva, contextualizada e interconectada. As produções digitais do LARP visam sempre à inclusão digital, ao entregar gratuitamente recursos confiáveis, que buscam favorecer um trabalho pedagógico rico e diversificado.

FLEMING, M.I.D'A.; MARTIRE, A.S.; GREGORI, A.M. Interactive Herculaneum Cyber-Archaeology and Education in the development of O Último Banquete em Herculano. Rev. Museu Arq. Etn., 35: 36-43, 2020.

Abstract: This article presents the development process of the first electronic game produced by Laboratório de Arqueologia Romana Provincial (LARP-MAE-USP) entitled O Último Banquete em Herculano (The Last Banquet in Herculaneum). The technical aspects of production are first discussed, listing the processes of material collection, script writing, 3D modelling and computer programming. Afterwards, the game's application in Education will be described, discussing the elaboration of a didactic guide for teachers with lesson plans and exercises.

Keywords: Cyber-Archaeology; Ancient Rome; Video games; Education; Basic education. 
Maria Isabel D'Agostino Fleming Alex da Silva Martire Alessandro Mortaio Gregori

\section{Referências bibliográficas}

Brougère, G. 2002. Jogo e Educação. Artes Médicas, Porto Alegre.

Costa, M.A.F. 2017. Ensino de história e games: dimensões práticas em sala de aula. Appris, Curitiba.
Fleming, M.I.D’A.; Gregori, A.M. 2017. Ciberarqueologia e Aprendizagem: Os Aplicativos Digitais do LARP no Diálogo Entre Universidade e Ensino Básico. Revista de Cultura e Extensão USP 17: 69-81. 